\title{
Effects of dietary spermine supplementation on cell cycle, apoptosis, and amino acid transporters of the thymus and spleen in piglets
}

\author{
Wei Cao ${ }^{1,2}$, Xianjian $\mathrm{Wu}^{1,2}$, Gang Jia, ${ }^{1,2}$, Hua Zhao ${ }^{1,2}$, Xiaoling Chen ${ }^{1,2}$, Caimei $\mathrm{Wu}^{1,2}$, Jingyi Cai ${ }^{1,2}$, \\ Jing Wang ${ }^{3}$, and Guangmang Liu ${ }^{1,2, *}$
}

\author{
* Corresponding Author: Guangmang Liu \\ Tel: +86-28-86290922, Fax: +86-28-86290922, \\ E-mail: liugm@sicau.edu.cn \\ ${ }^{1}$ Institute of Animal Nutrition, Sichuan Agricultural \\ University, Chengdu, Sichuan 611130, China \\ 2 Key Laboratory for Animal Disease-Resistance \\ Nutrition of China Ministry of Education, Chengdu, \\ Sichuan 611130, China \\ ${ }^{3}$ Maize Research Institute, Sichuan Agricultural \\ University, Chengdu, Sichuan 611130, China

\section{ORCID} \\ Wei Cao \\ https://orcid.org/0000-0002-6284-4300 \\ Xianjian Wu \\ https://orcid.org/0000-0002-7049-0207 \\ Gang Jia \\ https://orcid.org/0000-0003-1102-0683 \\ Hua Zhao \\ https://orcid.org/0000-0002-0334-4189 \\ Xiaoling Chen \\ https://orcid.org/0000-0002-5792-1703 \\ Caimei Wu \\ https://orcid.org/0000-0001-8437-0073 \\ Jingyi Cai \\ https://orcid.org/0000-0002-3194-0105 \\ Jing Wang \\ https://orcid.org/0000-0002-3624-8249 \\ Guangmang Liu \\ https://orcid.org/0000-0003-2385-7528
}

Submitted Nov 3, 2017; Revised Dec 12, 2017; Accepted Jan 24, 2018
Objective: This study investigated whether spermine supplementation could regulate cell cycle, apoptosis, and amino acid transporter-related genes expression in the thymus and spleen of early weaned piglets.

Methods: Eighty female piglets were randomly distributed to receive adequate nutrients supplemented with spermine $(0.4 \mathrm{mmol} / \mathrm{kg}$ body weight $/ 24 \mathrm{~h})$ or to be provided with restricted nourishment supplemented with normal saline for $7 \mathrm{~h}$ or 3,6 , or $9 \mathrm{~d}$ in pairs.

Results: Regardless of administration time, spermine supplementation significantly upregulated cyclin A2 gene expression but down-regulated p21 and cyclin D3 mRNA levels in the thymus and spleen and reduced cyclin $\mathrm{E} 2$ gene expression in the thymus of piglets $(\mathrm{p}<$ 0.05). Irrespective of the treatment period, the reduced Bax and caspase- 3 gene expressions and improved Bcl-2 mRNA level were observed in the thymus and spleen of spermine-administrated piglets $(\mathrm{p}<0.05)$. Regardless of supplementation time, spermine intake significantly enhanced the expressions of amino acid transporter-related genes (SLC1A1, SLC1A5, SLC7A1, SLC7A7, and SLC15A1) in both thymus and spleen, as well as SLC7A9 in the spleen of piglets $(p<0.05)$. In addition, extended spermine administration also markedly promoted cell proliferation, depressed apoptosis and modulated amino acid transport ( $\mathrm{p}<$ $0.05)$, and such effects were the greatest during prolonged spermine supplementation (6 d) compared to the other time periods $(\mathrm{p}<0.05)$.

Conclusion: Spermine supplementation may regulate cell cycle during the G1/S phase, suppress apoptosis and modulate amino acid transport. A period of $6 \mathrm{~d}$ of spermine supplementation is required to produce the optimal effects on nutritional implications.

Keywords: Spermine; Cell Cycle; Apoptosis; Amino Acid Transporters; Piglet

\section{INTRODUCTION}

Spermine, a low-molecular weight aliphatic biogenic amine naturally present in colostrum and milk, can contribute to synthesizing proteins and nucleic acids, modulating ion channel functions and calcium-related signal transduction, controlling cell membrane transport and metabolic processes, and increasing cell growth and proliferation [1-5]. Previous studies have shown that spermine plays an important role in regulating cell cycle progression of yeast during the oxidative stress response [6]. A scientific report has indicated that spermine also has protective effects against B cell antigen receptor-mediated apoptosis through upregulating Bcl-2 gene expression and down-regulating caspase mRNA abundance in rats [7]. The physiology of pigs is more similar to that of humans than are rats $[1,8]$. However, no information is available on the effects of spermine administration on the apoptosis of immune organs in piglets. Additionally, the precursor of spermine (i.e., arginine) can enhance amino acid absorption in the gut of piglets by up-regulating amino acid transporters, 
such as SLC7A7 and SLC7A1 [9]. Nevertheless, the relationship between spermine supplementation and amino acid absorption of the thymus and spleen remains largely unknown. As such, further study is important and necessary.

This study is a part of the series investigation about the effects of spermine supplementation on immune function and antioxidant status in the thymus and spleen of piglets [3]. Our objective was mainly to determine the effects of spermine supplementation on cell cycle, apoptosis, and amino acid transporters in the thymus and spleen of early weaned piglets. Here, representative gene expressions of the fields considered were assessed. Our findings may be potentially valuable for a better formula for piglets unable to be nursed by sow or even an ideal animal model for infants unable to be breastfed, providing scientific evidence for relieving weaning-related problems in livestock production.

\section{MATERIALS AND METHODS}

\section{Animal care and feeding}

The experimental procedures of this study was executed according to the actual law of animal protection (SYXK2014187) and the Animal Care and Use Committee of Sichuan Agricultural University, and obeyed the established guidelines confirmed by Laboratory Animals of the National Research Council for animal welfare and use. The basic formula milk used in the current study was made from $1 \mathrm{~kg}$ of formula milk (dry matter $87.5 \%$ ) and $4 \mathrm{~L}$ of drinking water to form the milk solution, and its nutritional levels met nutrient requirements for nursery piglets recommended by the National Research Council [10], which is presented in Table 1 and the same as in our previous study [3]. Ten healthy multiparous sows provided eighty $9 \mathrm{~d}$ old female piglets (Duroc $\times$ Landrace $\times$ Yorkshire) purchased from Pig Improvement Company. Afterward, they were acclimatized to the trial environment for $2 \mathrm{~d}$ before the experiment was started. Thus, they were $12 \mathrm{~d}$ old with body weight (BW) of $3.3 \mathrm{~kg}$ (standard error 0.03 ) when the experiment commenced, and the piglets were randomly allotted into eight groups ( $\mathrm{n}=10$ per group). All the piglets were housed individually in stainless-steel wire-bottomed metabolism cages at the Animal Nutrition Institute, Sichuan Agricultural University. The piglets were placed under spot heat lamps and bottle-fed with milk-based diet every $3 \mathrm{~h}$ between 06:00 and 24:00 daily. The match-restricted intake was used in the current study. Namely, the spermine-supplemented piglets obtained nutrient intake with spermine $(0.4 \mathrm{mmol} / \mathrm{kg} \mathrm{BW} / 24 \mathrm{~h}$; dissolved in normal saline) in formula milk ad libitum for $7 \mathrm{~h}$ or 3, 6, or $9 \mathrm{~d}$ (Groups SP-7 h, SP-3 d, SP-6 d, and SP-9 d, respectively), and matched control piglets received the same formula milk given to the spermine-treated piglets with physiological saline $(0.9 \% \mathrm{NaCl})$ once a day for $7 \mathrm{~h}$ or 3,6 , or $9 \mathrm{~d}$ (Groups Con-7 h, Con-3 d, Con-6 d, and Con-9 d, respec-
Table 1. Composition and nutrient level of the basal formula milk powder (87.5\% dry matter basis)

\begin{tabular}{lc}
\hline Items & $\%$ \\
\hline Ingredients & \\
Whole-milk powder (24\% crude protein) & 58.00 \\
Whey protein concentrate (34\% crude protein) & 25.00 \\
Casein & 5.70 \\
Coconut oil & 10.00 \\
CaH $_{2} \mathrm{PO}_{4}$ & 0.10 \\
Choline chloride (50\%) & 0.10 \\
Vitamin premix) & 0.10 \\
Mineral premix & \\
L-arginine $(98.5 \%)$ & 0.50 \\
DL-methionine (98.5\%) & 0.06 \\
L-lysine.HCl (78.5\%) & 0.06 \\
L-threonine (98\%) & 0.30 \\
L-tryptophan (98\%) & 0.03 \\
Total & 0.05 \\
Nutrient content & 100.00 \\
Digestible energy (kJ/kg) & \\
Crude protein (\%) & 18390 \\
Ca (\%) & 25.30 \\
Total phosphorus (\%) & 1.02 \\
Available phosphorus (\%) & 0.81 \\
Digestible lysine (\%) & 0.67 \\
Digestible methionine (\%) & 1.93 \\
Digestible arginine (\%) & 0.63 \\
\hline Vitami prem $\%$ rovided & 0.86 \\
\hline
\end{tabular}

1) Vitamin premix provided per kg powder diet: vitamin $A, 0.94 \mathrm{mg}$; vitamin $D_{3}$ $0.01 \mathrm{mg}$; vitamin $\mathrm{E}, 20 \mathrm{mg}$; vitamin $\mathrm{K}_{3}, 1 \mathrm{mg}$; vitamin $\mathrm{B}_{12}, 0.04 \mathrm{mg}$; riboflavin, 5 $\mathrm{mg}$; niacin, $20 \mathrm{mg}$; pantothenic acid, $15 \mathrm{mg}$; folic acid, $1.5 \mathrm{mg}$; thiamin, $1.5 \mathrm{mg}$; pyridoxine, $2 \mathrm{mg}$; biotin, $0.1 \mathrm{mg}$.

2) Mineral premix provided per kg powder diet: Zn, 90 mg; Mn, 4.0 mg; Fe, 90 mg; $\mathrm{Cu}, 6.0 \mathrm{mg} ; \mathrm{l}, 0.2 \mathrm{mg} ; \mathrm{Se}, 0.3 \mathrm{mg}$.

tively). The piglets had free access to drinking water provided by water nipples. The ambient temperature and relative humidity of the room were kept at approximately $30^{\circ} \mathrm{C}$ and $50 \%$ to $60 \%$, respectively. Spermine dosage and spermine-administration time employed in this experiment were selected based on a previous study [11].

\section{Tissue sample collection}

At the termination of $7 \mathrm{~h}, 3 \mathrm{~d}, 6 \mathrm{~d}$, and $9 \mathrm{~d}$ feeding trails (at this time, the piglets were $12,15,18$, and $21 \mathrm{~d}$ old, respectively), all the piglets were anesthetized with an intravenous injection of pentobarbital sodium (15 mg/kg BW), and sacrificed by exsanguination for thymus and spleen samples. The thymus and spleen of all piglets were quickly procured and washed with ice-cold normal saline $\left(0.9 \% \mathrm{NaCl} ; 4^{\circ} \mathrm{C}\right)$, snap frozen in liquid nitrogen, and then preserved at $-80^{\circ} \mathrm{C}$ for further real time-polymerase chain reaction (RT-PCR) analysis.

\section{Total RNA extraction}

The total RNA of the thymus and spleen was extracted as previously described [3]. Approximately $0.1 \mathrm{~g}$ of the frozen 
thymus or spleen tissues was promptly placed in prepared mortars and ground in liquid nitrogen. To remove excrescent samples, the powder was homogenized in $1 \mathrm{~mL}$ TRIzol reagent (Takara, Dalian, China) and centrifuged at 12,000 $\times \mathrm{g}$ for $10 \mathrm{~min}$ at $4^{\circ} \mathrm{C}$ until the samples were adequately dissolved, and the supernatant was obtained. The $200 \mu \mathrm{L}$ trichloromethane was added to the supernatant, and the mixture was agitated for $20 \mathrm{~s}$. After standing for $5 \mathrm{~min}$, the mixture was centrifuged at $12,000 \times \mathrm{g}$ for $15 \mathrm{~min}$ at $4^{\circ} \mathrm{C}$, and $500 \mu \mathrm{L}$ of supernatant (on the white band) was collected. Afterward, equal volumes of isopropyl alcohol $(500 \mu \mathrm{L})$ were added to $500 \mu \mathrm{L}$ of the supernatant, and the mixtures were slightly overturned for $5 \mathrm{~s}$ to mix the compound; the compound was centrifuged at $12,000 \times \mathrm{g}$ for $10 \mathrm{~min}$ at $4^{\circ} \mathrm{C}$ after standing for $10 \mathrm{~min}$. Following this process, the supernatant was discarded, and the precipitate was retained; $1 \mathrm{~mL}$ of $75 \%$ ethyl alcohol was added to the precipitate to scour the residual isopropyl alcohol and then centrifuged at $12,000 \times \mathrm{g}$ for $5 \mathrm{~min}$ at $4^{\circ} \mathrm{C}$. Next, $75 \%$ ethyl alcohol was removed, and the mixture was evaporated for 2 to $3 \mathrm{~min}$; then, about $40 \mu \mathrm{L}$ sterile water was added to dissolve the RNA precipitate. Aliquots of $4 \mu \mathrm{g}$ RNA samples were used to detect their integrity by agarose gel electrophoresis (1\%). Moreover, RNA concentration and quality were examined by Nano Drop 2000/2000C spectrophotometric analysis (Thermo Fisher Scientific, Wilmington, DE, USA) at 260 and $280 \mathrm{~nm}$. The ratios of absorption $(260 / 280 \mathrm{~nm})$ of all samples were maintained at 1.8 to 2.0 .

\section{Synthesis of cDNA and real-time fluorescent quantitative PCR determination}

For each sample, $1 \mu \mathrm{g}$ of total RNA sample was used to synthesize cDNA by real-time RT-PCR according to the instructions of the commercial reverse transcription kit with gDNA Eraser (Takara, China). The cDNA was preserved at $-20^{\circ} \mathrm{C}$ for relative fluorescent quantitative PCR assay. Based on the pig sequence, primers of the corresponding genes were designed by the Primer Express Software (version 3.0; Applied Biosystems, Foster City, CA, USA) and synthesized by TaKaRa Biotechnology Company (Takara, China), as shown in Table 1. The reaction of real-time PCR for quantification was performed by a real-time PCR system (ABI 7900HT, Applied Biosystems, USA) according to the instructions of the SYBR Green I PCR reagent kit. The mixture $(8 \mu \mathrm{L})$ of real-time fluorescent quantitative PCR was supplied as follows: SYBR Premix Ex Taq II with ROX Reference Dye $(4 \mu \mathrm{L})$, cDNA $(0.8$ $\mu \mathrm{L}), 10 \mu \mathrm{M}$ of forward primer $(0.8 \mu \mathrm{L})$ and reverse primer $(0.8 \mu \mathrm{L})$, and $\mathrm{ddH} 2 \mathrm{O}(1.6 \mu \mathrm{L})$. The thermal cycler conditions for PCR included the following: denaturation $\left(95^{\circ} \mathrm{C}\right.$ for $\left.10 \mathrm{~s}\right)$, 42 cycles $\left(95^{\circ} \mathrm{C}\right.$ for $10 \mathrm{~s}$; annealing temperature [Table 2] for $35 \mathrm{~s})$, and extension step $\left(72^{\circ} \mathrm{C}\right.$ for $\left.15 \mathrm{~s}\right)$. In this study, the housekeeping gene ( $\beta$-actin) was employed as the reference gene transcript to normalize the expression levels of the other target genes. The relative expression quantity of the target genes was calculated according to the threshold cycle number as described in a previous study [12]. The relative mRNA expression results of the target genes were analyzed according to the $2^{-\Delta \Delta C t}$ method as described previously [13] and were represented as their ratios to $\beta$-actin mRNA. Therefore, relative expression of target genes in C-7 served as 1 fold in the current experiment.

\section{Statistical analysis}

All obtained results were expressed as means \pm standard error of the mean and statistically subjected to two-way analysis of variance (ANOVA) followed by Duncan's multiple range to separate statistical differences among the treatment groups, and determined for normality and homogeneity of variances using Shapiro-Wilk's W-test and Levene's test, respectively. The main effects in our experimental model involved spermine level $(0$ or $0.4 \mathrm{mmol} / \mathrm{kg} \mathrm{BW} / 24 \mathrm{~h})$, treatment time $(7 \mathrm{~h}$, $3 \mathrm{~d}, 6 \mathrm{~d}$, or $9 \mathrm{~d}$ ) and interactions. The p-values $<0.05$ were applied to statistical differences. Correlations among cell cycle, apoptosis and amino acid transporters were completed by Pearson correlation analysis. All statistical analyses were achieved using the general linear model procedure of SPSS 21.0 (SPSS Inc., Chicago, IL, USA).

\section{RESULTS}

\section{Cell cycle-related genes expression in the thymus and spleen}

The mRNA levels of cell cycle-related genes in the thymus are illustrated in Figure 1. Spermine ingestion significantly increased the gene expressions of cyclin A2 (Group SP-3 d vs Group Con-3 d; Group SP-6 d vs Group Con-6 d; Group SP-9 d vs Group Con-9 d) but markedly decreased mRNA expressions of p21 (Group SP-6 d vs Group Con-6 d; Group SP-9 d vs Group Con-9 d), cyclin D3 (Group SP-6 d vs Group Con-6 d), and cyclin E2 (Group SP-6 d vs Group Con-6 d; $\mathrm{p}<0.05)$. Moreover, cyclin A2 gene expression was significantly improved with prolonged spermine supplementation (6d), and then it decreased afterward $(\mathrm{p}<0.05)$. The mRNA expression of p21 was lower at $6 \mathrm{~d}$ of spermine intake compared with those observed at $7 \mathrm{~h}, 3 \mathrm{~d}$, or $9 \mathrm{~d}$ of spermine ingestion $(\mathrm{p}<0.05)$. Cyclin D3 mRNA level was the highest in piglets that received spermine for $7 \mathrm{~h}$ and $3 \mathrm{~d}$ followed by those with $9 \mathrm{~d}$ of spermine intake, and the lowest was observed in piglets fed with spermine supplementation for $6 \mathrm{~d}(\mathrm{p}<0.05)$. Gene expression of cyclin E2 was markedly reduced after $6 \mathrm{~d}$ of spermine administration $(\mathrm{p}<0.05)$, which plateaued thereafter.

As shown in Figure 2, in the spleen, gene expression of cyclin A2 (Group SP-3 d vs Group Con-3 d; Group SP-6 d vs Group Con-6 d; Group SP-9 d vs Group Con-9 d) significantly increased but p21 (Group SP-3 d relative to Group Con-3 d) 
Table 2. Primer sequences of the target and reference genes of the thymus and spleen in piglets

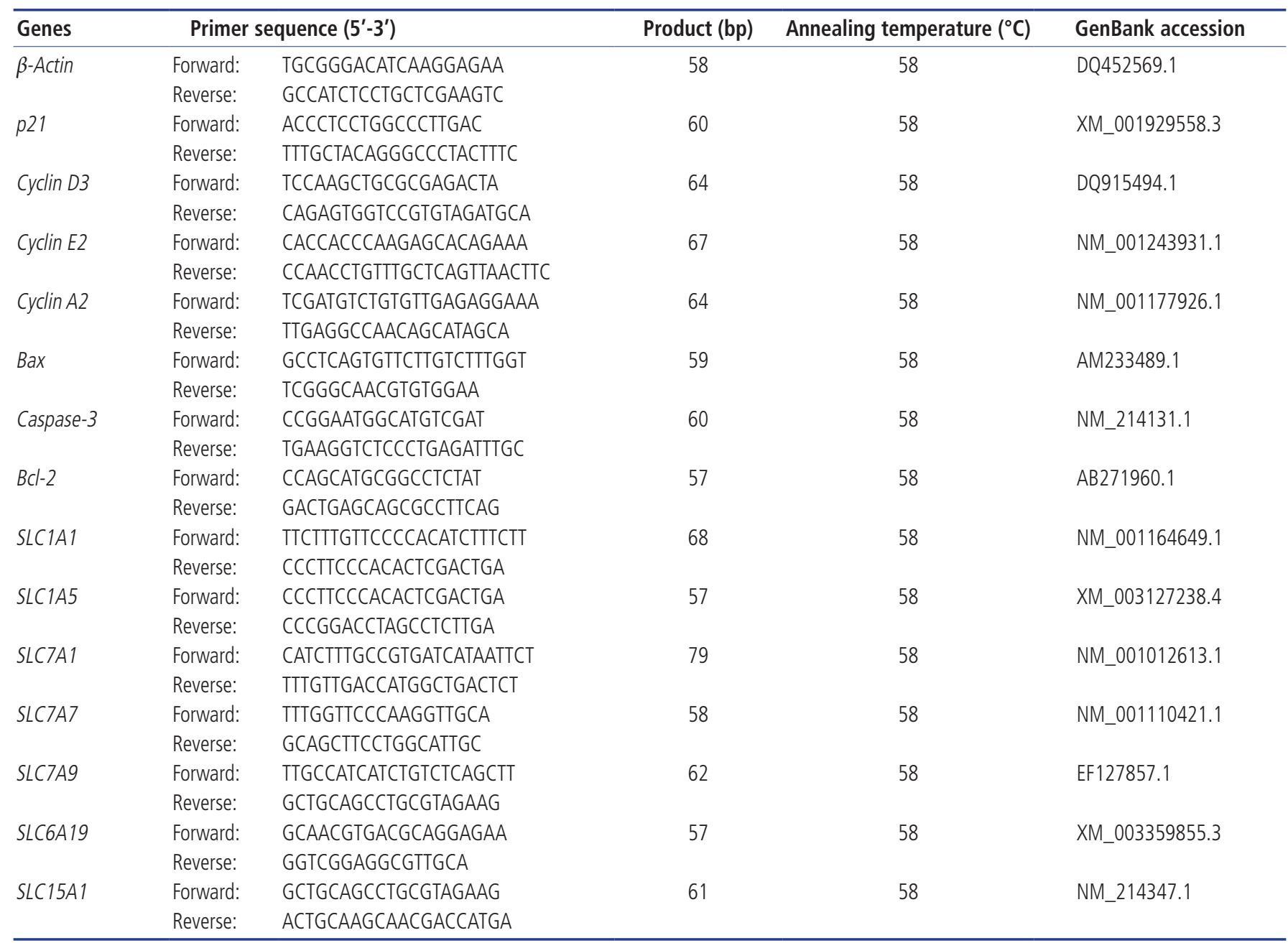

p21, cyclin A2, cyclin D3 and cyclin E2, cell cycle related factor; Bax and BCl-2, apoptosis related factor; Caspase-3, cysteine-aspartic acid protease factor 3; SLC, amino acid transport related factor.

and cyclin D3 (Group SP-9 d relative to Group Con-9 d) markedly decreased $(\mathrm{p}<0.05)$, and no significant difference was found in cyclin E2 mRNA abundance that was induced by spermine intake ( $p>0.05)$. In addition, cyclin A2 mRNA level was significantly enhanced with extended spermine supplementation of up to $6 \mathrm{~d}$, and a decrease was observed afterward $(\mathrm{p}<0.05)$. Expression of p21 gene decreased with the extension of spermine administration to up to $6 \mathrm{~d}(\mathrm{p}<0.05)$, and no marked differences were observed with further extension of spermine ingestion ( $p>0.05)$. Cyclin D3 mRNA expression was maximum in the piglets supplemented with spermine for $7 \mathrm{~h}$, and the minimum expression was observed after $6 \mathrm{~d}$ of spermine ingestion $(\mathrm{p}<0.05)$.

\section{Alterations of apoptosis-related genes expression in the thymus and spleen}

Figure 3 shows that spermine administration promoted a reduction in Bax (Group SP-3 d vs Group Con-3 d) and caspase-3 (Group SP-3 d vs Group Con-3 d; Group SP-6 d vs
Group Con-6 d; Group SP-9 d vs Group Con-9 d) mRNA. However, an improvement in $\mathrm{Bcl}-2$ gene expression (Group SP-3 d vs Group Con-3 d; Group SP-6 d vs Group Con-6 d; Group SP-9 d vs Group Con-9 d) was noted in the thymus $(\mathrm{p}<0.05)$. Furthermore, Bax gene expression was highest in the piglets provided with $7 \mathrm{~h}$ of spermine and lowest for piglets supplied with spermine for $6 \mathrm{~d}(\mathrm{p}<0.05)$. The gene expression of caspase- 3 decreased with prolonged spermine supplementation of up to $6 \mathrm{~d}(\mathrm{p}<0.05)$, and a plateau was observed afterward ( $p>0.05$ ). Bcl-2 mRNA level was significantly enhanced with extended spermine administration of up to $6 \mathrm{~d}$, and then a reduction was found thereafter $(\mathrm{p}<0.05)$.

As presented in Figure 4, spermine supplementation significantly reduced mRNA expressions of Bax and caspase-3. Conversely, enhanced $B c l-2$ gene expression was observed in the spleen of the piglets (Group SP-6 d relative to Group Con-6 d; Group SP-9 d relative to Group Con-9 d; p<0.05). In addition, significant down-regulation of Bax gene expression was observed with extended spermine intake of up to 6 

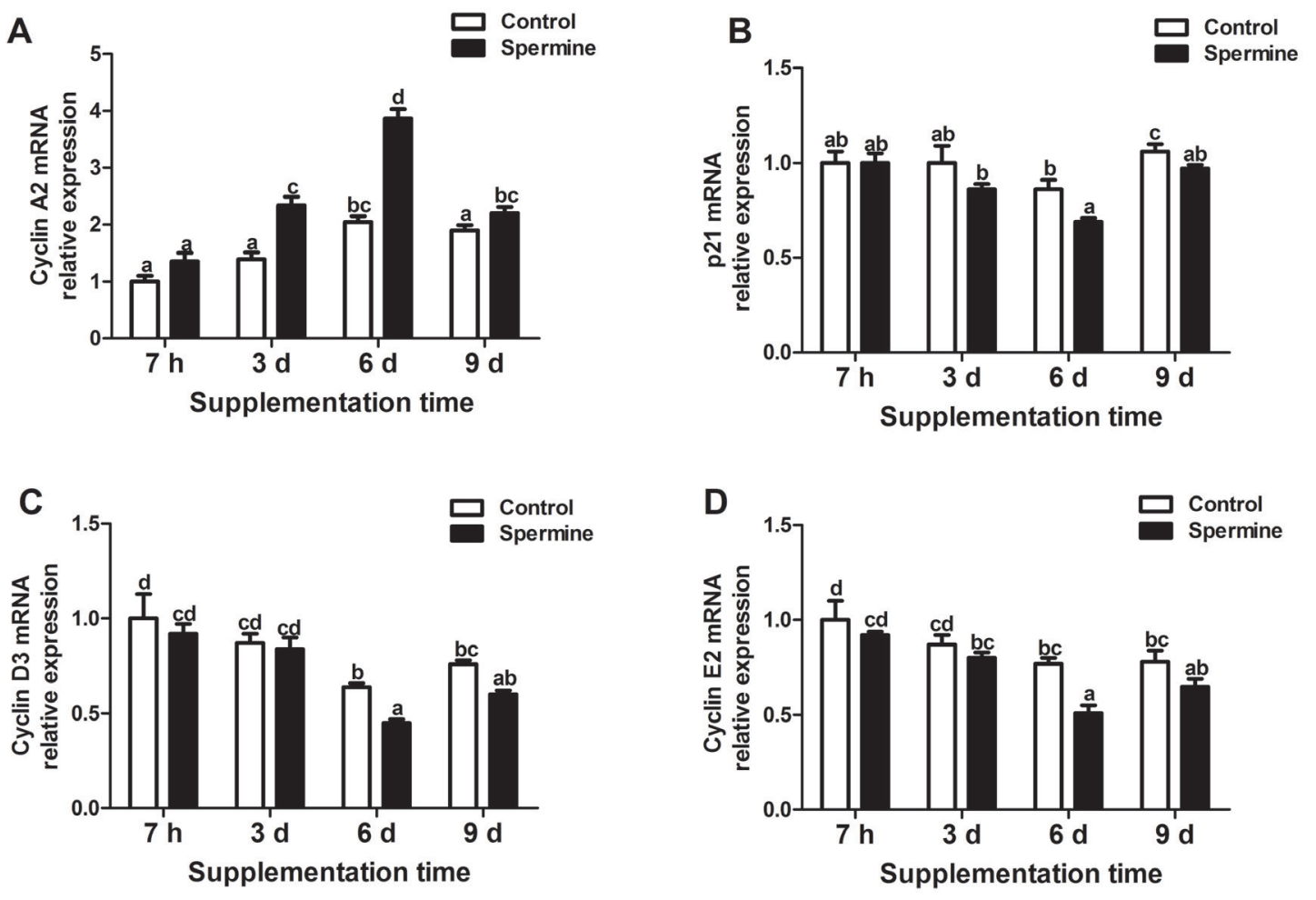

Figure 1. Relative mRNA levels of cyclin A2 (A), p21 (B), cyclin D3 (C), and cyclin E2 (D) in the thymus of piglet fed diets with or without spermine for $7 \mathrm{~h}, 3 \mathrm{~d}, 6 \mathrm{~d}$, or $9 \mathrm{~d}$. Cyclin A2, p21, cyclin D3, and cyclin E2, cell cycle related factor. Values are means \pm standard error of the mean $(n=6)$. ${ }^{a, b, c, d}$ Means bearing different letters differ significantly $(p<0.05)$.
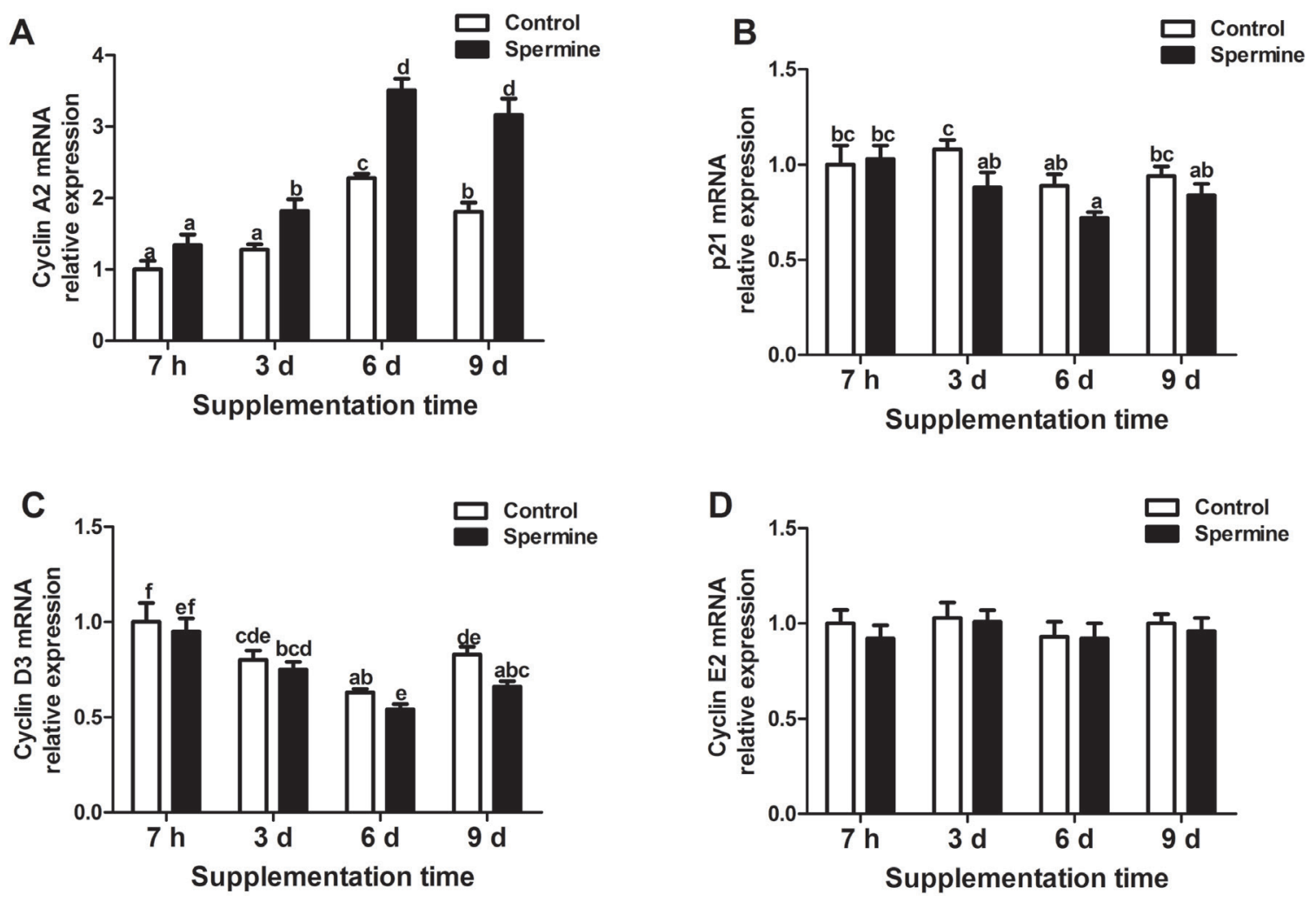

Figure 2. Relative mRNA levels of cyclin A2 (A), p21 (B), cyclin D3 (C), and cyclin E2 (D) in the spleen of piglet fed diets with or without spermine for 7 h, $3 \mathrm{~d}, 6 \mathrm{~d}$, or $9 \mathrm{~d}$. Cyclin A2, p21, cyclin D3, and cyclin E2, cell cycle related factor. Values are means \pm standard error of the mean $(n=6)$. ${ }^{a, b, c, d, e, f}$ Means bearing different letters differ significantly $(p<0.05)$ 

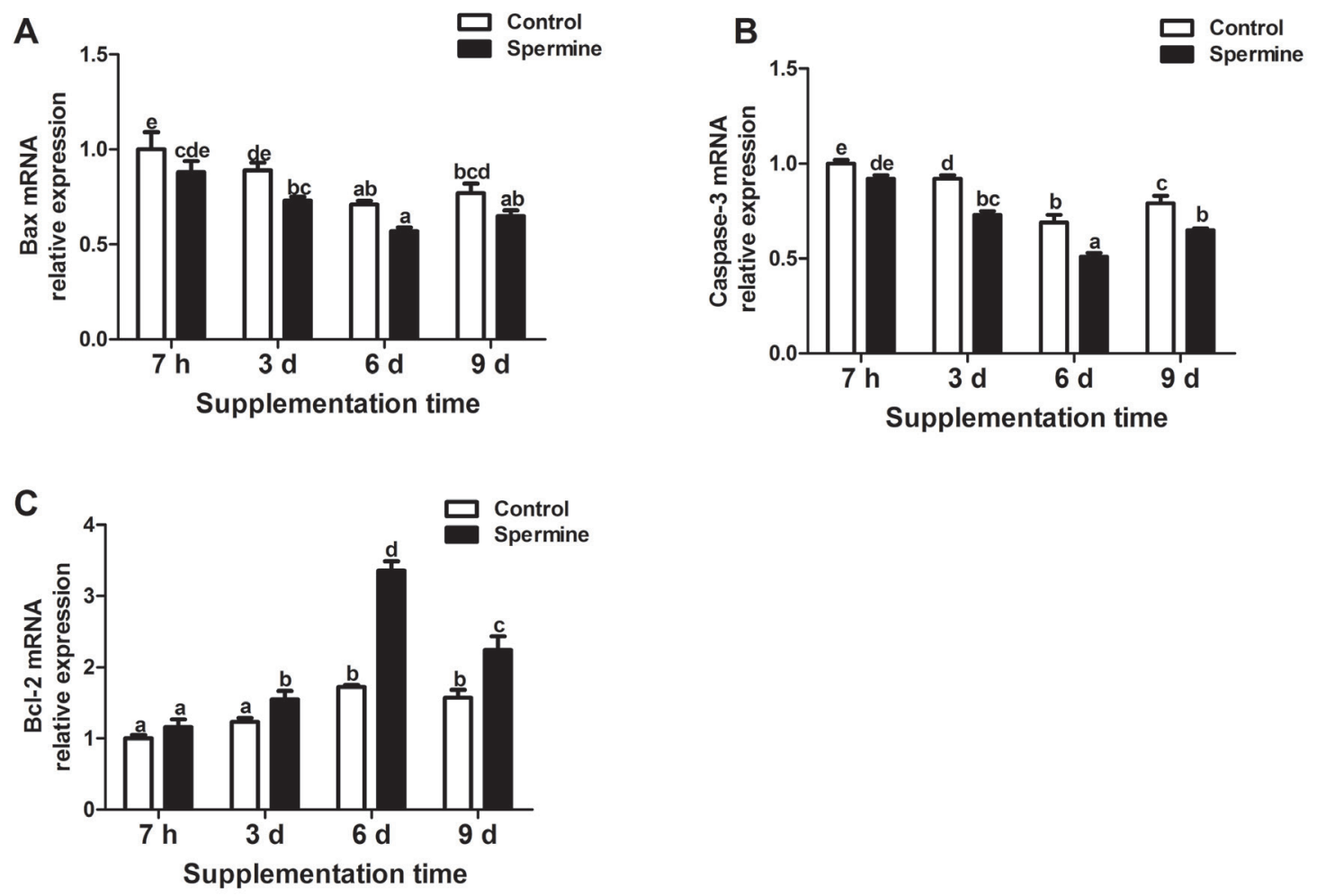

Figure 3. Relative mRNA levels of Bax (A), Caspase-3 (B), Bcl-2 (C) in the thymus of piglet fed diets with or without spermine for $7 \mathrm{~h}, 3 \mathrm{~d}, 6 \mathrm{~d}$, or $9 \mathrm{~d}$. Bax and Bcl-2, apoptosis related factor; Caspase-3, cysteine-aspartic. Values are means \pm standard error of the mean $(n=6)$. a,b,c,de Means bearing different letters differ significantly $(p<0.05)$.
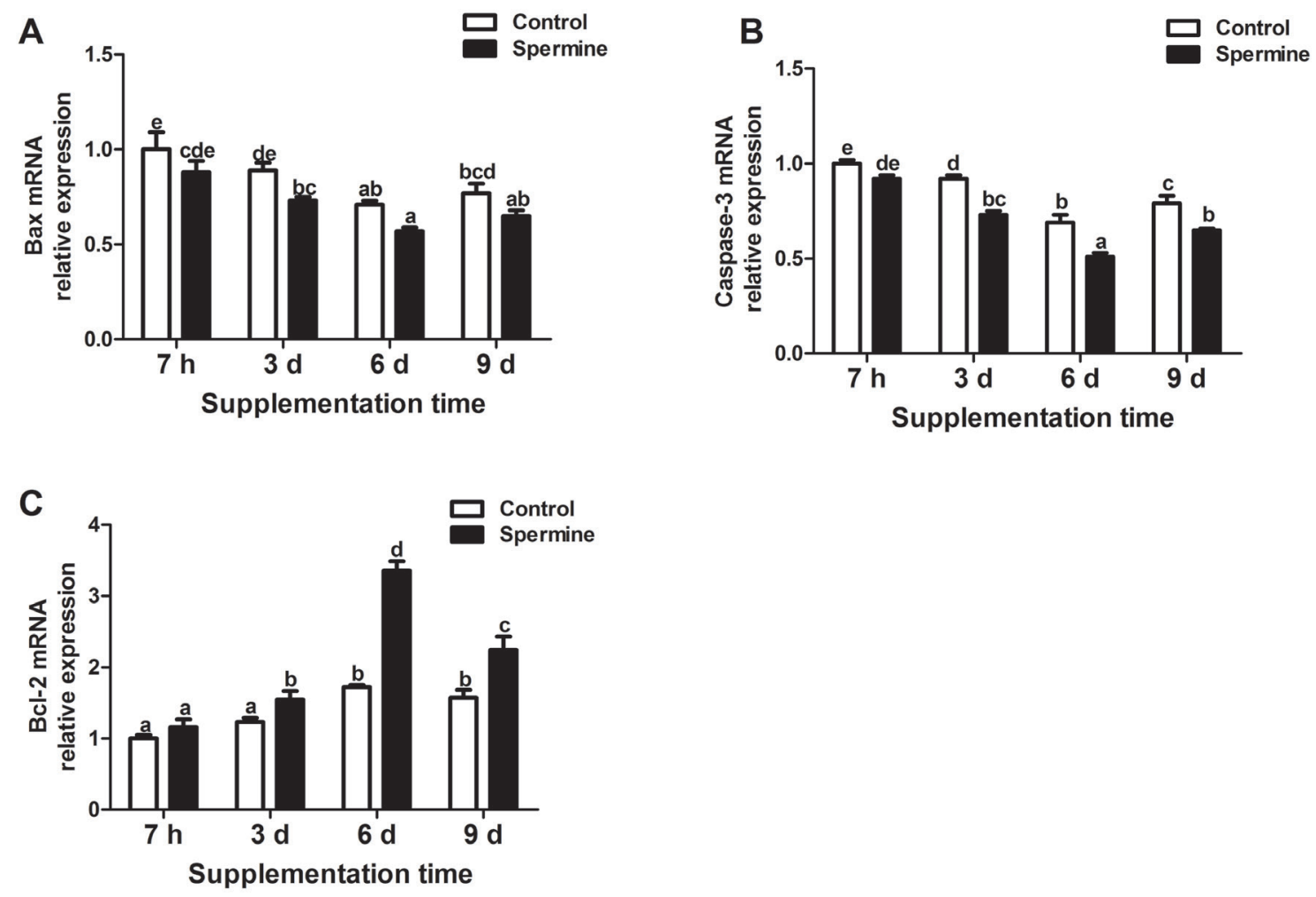

Figure 4. Relative mRNA levels of Bax (A), Caspase-3 (B), Bcl-2 (C) in the spleen of piglet fed diets with or without spermine for $7 \mathrm{~h}, 3 \mathrm{~d}, 6 \mathrm{~d}$, or $9 \mathrm{~d}$. Bax and Bcl-2, apoptosis related factor; Caspase-3, cysteine-aspartic. Values are means \pm standard error of the mean $(n=6)$. ${ }^{a, b, c, d, f}$ Means bearing different letters differ significantly $(p<0.05)$. 
$\mathrm{d}$, and up-regulation was observed thereafter $(\mathrm{p}<0.05)$. Maximum caspase-3 gene expression for the piglets was obtained at $7 \mathrm{~h}$ of spermine ingestion, and the minimum expression was observed after $6 \mathrm{~d}$ of spermine administration $(\mathrm{p}<0.05)$. The mRNA expression of Bcl-2 improved with extension of spermine supplementation to up to $6 \mathrm{~d}$, and then decreased afterward $(\mathrm{p}<0.05)$.

\section{Changes of amino acid transporters mRNA levels in the thymus and spleen}

Table 3 reveals the changes in the amino acid transporters mRNA levels of the thymus. Expressions of amino acid transport-related genes, such as SLC1A1, SLC1A5, SLC7A1, SLC7A7, and $S L C 15 A 1$, were significantly increased by spermine supplementation (Group SP-3 d vs Group Con-3 d; Group SP-6 d vs Group Con-6 d; Group SP-9 d vs Group Con-9 d; p<0.05). However, SLC7A9 and SLC6A19 mRNA abundances remained uninfluenced ( $\mathrm{p}>0.05)$. Additionally, the mRNA expressions of SLC1A1, SLC1A5, SLC7A1, SLC7A7, and SLC15A1 significantly increased with extended spermine supplementation of up to $6 \mathrm{~d}$ before they subsequently decreased $(\mathrm{p}<0.05)$. Extended spermine intake did not affect SLC7A9 and SLC6A19 gene expressions ( $\mathrm{p}>0.05$ ).

Based on the findings shown in Table 4, spermine supplementation markedly improved the gene expressions of SLC1A1 and SLC7A7 (Group SP-6 d relative to Group Con-6 d; Group SP-9 d relative to Group Con-9 d), SLC1A5 (Group SP-3 d vs Group Con-3 d; Group SP-6 d vs Group Con-6 d; Group SP-9 d vs Group Con-9 d), SLC7A1 (Group SP-6 d relative to Group Con-6 d), SLC7A9 (Group SP-7 h vs Group Con-7 h; Group SP-3 d vs Group Con-3 d; Group SP-6 d vs Group Con-6 d; Group SP-9 d vs Group Con-9 d), and SLC15A1 (Group SP-9 $\mathrm{d}$ relative to Group Con-9 d) $(\mathrm{p}<0.05)$ and did not influence SLC6A19 mRNA level in the spleen of piglets ( $p>0.05)$. Furthermore, SLC1A5, SLC7A7, and SLC7A9 mRNA levels were significantly enhanced with extension of spermine administration to up to $6 \mathrm{~d}$, and their reductions were observed thereafter $(\mathrm{p}<0.05)$. The gene expression of SLC1A1 was minimum in piglets fed for $7 \mathrm{~h}$ with spermine supplementation and maximum at $6 \mathrm{~d}$ of spermine administration $(\mathrm{p}<0.05)$. SLC15A1 mRNA abundance was maxinum at $6 \mathrm{~d}$ of spermine intake $(\mathrm{p}<0.05)$. No significant differences were obtained for SLC7A1 and SLC6A19 gene expressions observed at the four time periods ( $\mathrm{p}>0.05)$.

Table 3. Effects of spermine supplementation on amino acid transporters mRNA levels in the thymus of piglets

\begin{tabular}{|c|c|c|c|c|c|c|c|c|c|c|c|c|}
\hline \multirow{3}{*}{ Items } & \multicolumn{8}{|c|}{ Treatment time } & \multirow{3}{*}{ SEM } & \multirow{2}{*}{\multicolumn{3}{|c|}{$p$-value }} \\
\hline & \multicolumn{2}{|c|}{$7 \mathrm{~h}$} & \multicolumn{2}{|l|}{$3 d$} & \multicolumn{2}{|c|}{$6 \mathrm{~d}$} & \multicolumn{2}{|c|}{$9 d$} & & & & \\
\hline & Con & SP & Con & SP & Con & SP & Con & SP & & SP & Time & SPxtime \\
\hline SLC1A1 & $1.00^{\mathrm{a}}$ & $1.19^{\mathrm{a}}$ & $1.40^{\mathrm{ab}}$ & $2.39^{d}$ & $2.32^{\text {cd }}$ & $4.34^{f}$ & $1.83^{b c}$ & $3.11^{\mathrm{e}}$ & 0.17 & 0.000 & 0.000 & 0.000 \\
\hline SLC1A5 & $1.00^{\mathrm{a}}$ & $1.38^{\mathrm{a}}$ & $1.45^{\mathrm{a}}$ & $2.18^{b}$ & $2.28^{b}$ & $4.28^{b}$ & $2.03^{b}$ & $2.73^{c}$ & 0.14 & 0.000 & 0.000 & 0.000 \\
\hline SLC7A1 & $1.00^{\mathrm{a}}$ & $1.27^{\mathrm{a}}$ & $1.41^{\mathrm{a}}$ & $2.31^{b}$ & $3.00^{c}$ & $4.73^{d}$ & $2.10^{b}$ & $3.26^{c}$ & 0.18 & 0.000 & 0.000 & 0.000 \\
\hline SLC7A7 & $1.00^{\mathrm{a}}$ & $1.28^{\mathrm{a}}$ & $1.13^{\mathrm{a}}$ & $2.09^{b}$ & $2.09^{b}$ & $5.46^{d}$ & $1.94^{b}$ & $3.36^{c}$ & 0.21 & 0.000 & 0.000 & 0.000 \\
\hline SLC7A9 & 1.00 & 1.05 & 1.06 & 0.94 & 1.03 & 1.12 & 0.98 & 1.11 & 0.03 & 0.496 & 0.803 & 0.423 \\
\hline SLC6A19 & 1.00 & 1.03 & 1.09 & 1.10 & 1.03 & 1.08 & 0.98 & 1.13 & 0.03 & 0.370 & 0.827 & 0.886 \\
\hline SLC15A1 & $1.00^{\mathrm{a}}$ & $1.32^{\mathrm{a}}$ & $1.24^{\mathrm{a}}$ & $1.98^{b}$ & $1.96^{b}$ & $3.52^{d}$ & $2.03^{b}$ & $2.74^{c}$ & 0.13 & 0.000 & 0.000 & 0.004 \\
\hline
\end{tabular}

SEM, standard error of the mean; Con, control diet; SP, spermine-supplemented diet.

Values are means \pm SEM $(n=6)$.

${ }^{a \cdot f}$ Means in the same row bearing different superscripts differ significantly.

Table 4. Effects of spermine administration on amino acid transporters mRNA expressions in the spleen of piglets

\begin{tabular}{|c|c|c|c|c|c|c|c|c|c|c|c|c|}
\hline \multirow{3}{*}{ Items } & \multicolumn{8}{|c|}{ Treatment time } & \multirow{3}{*}{ SEM } & \multirow{2}{*}{\multicolumn{3}{|c|}{$p$-value }} \\
\hline & \multicolumn{2}{|c|}{$7 \mathrm{~h}$} & \multicolumn{2}{|c|}{$3 d$} & \multicolumn{2}{|c|}{$6 \mathrm{~d}$} & \multicolumn{2}{|c|}{$9 d$} & & & & \\
\hline & Con & SP & Con & SP & Con & $S P$ & Con & SP & & SP & Time & SPxtime \\
\hline SLC1A1 & $1.00^{\mathrm{a}}$ & $1.08^{\mathrm{a}}$ & $0.97^{\mathrm{a}}$ & $1.23^{\mathrm{ab}}$ & $1.47^{b c}$ & $2.66^{d}$ & $1.09^{a}$ & $1.81^{c}$ & 0.09 & 0.000 & 0.000 & 0.000 \\
\hline SLC1A5 & $1.00^{\mathrm{a}}$ & $1.32^{\mathrm{ab}}$ & $1.30^{\mathrm{a}}$ & $1.82^{b c}$ & $2.04^{c}$ & $3.76^{\mathrm{e}}$ & $1.50^{\mathrm{ab}}$ & $2.72^{d}$ & 0.14 & 0.000 & 0.000 & 0.001 \\
\hline SLC7A1 & $1.00^{\mathrm{a}}$ & $1.16^{\mathrm{a}}$ & $1.11^{\mathrm{a}}$ & $1.14^{\mathrm{a}}$ & $1.09^{\mathrm{a}}$ & $1.39^{b}$ & $1.04^{\mathrm{a}}$ & $1.17^{\mathrm{a}}$ & 0.04 & 0.018 & 0.129 & 0.349 \\
\hline SLC7A7 & $1.00^{\mathrm{a}}$ & $1.19^{\mathrm{a}}$ & $1.34^{\mathrm{ab}}$ & $1.75^{b c}$ & $2.09^{c}$ & $3.86^{\mathrm{e}}$ & $1.71^{b c}$ & $2.54^{d}$ & 0.14 & 0.000 & 0.000 & 0.000 \\
\hline SLC7A9 & $1.00^{\mathrm{a}}$ & $1.38^{b}$ & $1.33^{\mathrm{ab}}$ & $1.87^{c}$ & $1.86^{c}$ & $3.39^{e}$ & $1.57^{b c}$ & $2.30^{d}$ & 0.11 & 0.000 & 0.000 & 0.000 \\
\hline SLC6A19 & 1.00 & 1.01 & 0.94 & 0.99 & 1.17 & 1.13 & 0.94 & 1.12 & 0.03 & 0.356 & 0.127 & 0.526 \\
\hline SLC15A1 & $1.00^{\mathrm{ab}}$ & $1.06^{\mathrm{abc}}$ & $0.99^{\mathrm{ab}}$ & $1.32^{\mathrm{bcd}}$ & $1.25^{\mathrm{abcd}}$ & $1.58^{d}$ & $0.94^{\mathrm{a}}$ & $1.39^{\mathrm{cd}}$ & 0.05 & 0.001 & 0.018 & 0.405 \\
\hline
\end{tabular}

SEM, standard error of the mean; Con, control diet; SP, spermine-supplemented diet.

Values are means \pm SEM $(n=6)$.

${ }^{\text {a.e }}$ Means in the same row bearing different superscripts differ significantly. 


\section{DISCUSSION}

Spermine (as one of natural milk components) plays dominating roles in the gut, such as promoting intestinal cell growth and proliferation, alleviating intestinal dysfunction, and regulating intestinal metabolism $[4,5,14]$. Appropriate dosage of spermine $(0.4 \mathrm{mmol} / \mathrm{kg} \mathrm{BW} / 24 \mathrm{~h})$ was beneficial to the growth and development of cells according to a previous study [11]. Thus, a similar dose was used in this experiment. The thymus and spleen are the crucial central immune organ and the largest peripheral immune organ, respectively, which play important roles in immune reaction and prevention against numerous biological stress responses of the body. Therefore, maintaining the normal functions of immune organs or promoting their development is essential for animal growth and health.

\section{Spermine administration changes expression of cell} cycle-related genes in the thymus and spleen

Weaning stress may compromise cells. This effect is closely involved in animal reproduction, growth, and health through damaging DNA and inhibiting cell proliferation. Cell proliferation is relevant to cell cycle. The cell cycle is composed of four phases, including G1, S, G2, and M, and it is regulated by cyclins, cyclin-dependent kinases, and cyclin-dependent kinase inhibitors [15]. G1 phase plays a crucial role in providing substances and energy for DNA replication during the $S$ phase. Considering the effect of spermine, we assayed G1 phase-related genes, such as p21, cyclin E2, and cyclin D3 in the thymus and spleen. p21, a cyclin-dependent kinase inhibitor, is known as the regulator of the G1/S phase checkpoint and can inhibit cell cycle progression processes by suppressing cell proliferation $[6,16]$. Cyclin E2, a novel G1 cyclin, can combine with cyclin-dependent kinase-2 to accelerate the transition of cell from G1 to S phase [17]; however, the gene expression of cyclin E2 is rather low in normally proliferating cells and high in diseased cells [17]. Additionally, widespread research had been conducted to understand cyclin D3 function. Cyclin D3 is the important regulatory factor for initiating the transition from $\mathrm{G} 1$ to $\mathrm{S}$ phase, and it is positively associated with tumor progression and formation [18]. In the present study, spermine supplementation significantly decreased p 21 and cyclin D3 gene expressions in the thymus and spleen. Cyclin E2 mRNA level was markedly reduced in the thymus, whereas it was not significantly affected by spermine intake in the spleen, which may be due to tissue differences in the organs. Further correlation analysis showed that p21 mRNA level was positively correlated with gene expressions of cyclin E2 $\left(r_{\text {thymus }}=+0.710, P_{\text {thymus }}=0.049^{*}\right)$ and cyclin D3 $\left(r_{\text {spleen }}=\right.$ $\left.+0.806, P_{\text {spleen }}=0.016^{*}\right)$, hinting that spermine supplementation promoted cell proliferation through decreased p21 gene expression may be partly due to induced cyclin E2 and cyclin
D3 mRNA levels. To further study the effect of spermine ingestion on other phases of the cell cycle, cyclin A2 gene was also evaluated.

In mammalian cell lines, cyclin A2, the main controlling factor of the progress of mitosis, is essential for DNA replication during prophase of mitosis, and the transition of pivotal points, such as the G1-S and G2-M phases, have an important regulating effect on cell cycle [19]. Results revealed that a higher level of cyclin A2 gene in both thymus and spleen was observed with spermine administration, and cyclin A2 mRNA expression had substantial relation to p21 gene expression $\left(r_{\text {spleen }}=-0.912, P_{\text {spleen }}=0.002^{\star *} ; r_{\text {thymus }}=-0.864\right.$, $\left.P_{\text {thymus }}=0.006^{* *}\right)$ and cyclin D3 mRNA level $\left(r_{\text {spleen }}=-0.888\right.$, $\left.P_{\text {spleen }}=0.003^{* *} ; r_{\text {thymus }}=-0.876, P_{\text {thymus }}=0.004^{* *}\right)$, which implies that spermine administration can effectively modulate cell cycle by interaction of such genes. In addition, prolonged spermine administration also markedly decreased p21 and cyclin D3 mRNA levels in the thymus and spleen, down-regulated cyclin E2 gene expression in the thymus and increased cyclin A2 mRNA expression both in the thymus and spleen, with their minimum/maximum expressions at $6 \mathrm{~d}$ after spermine supplementation.

Overall, findings revealed that spermine supplementation can regulate the cell cycle, and such effects were maximized after extended spermine supplementation (6 d). Certainly, further investigation is essential for revealing the detailed mechanism by which spermine administration regulated cell cycle mRNA level. Accumulating evidences have indicated that cell cycle checkpoints appear to link cell cycle to apoptosis. Therefore, we further investigated the effects of spermine supplementation on apoptosis gene expression of thymus and spleen in piglets.

\section{Spermine supplementation alters apoptosis-related gene expressions of the thymus and spleen}

During normal conditions, apoptosis removes abnormal or damaged cells, maintains the normal function of immune system, and participates in histogenesis during prenatal development, thus adjusting the normal growth of tissues $[18,20]$. Previous study indicated that preventing apoptosis can lead to extensive variety of diseases. Nevertheless, uncontrolled apoptosis can be initiated by excessive production of oxidants, which cause pathogenic and damaging effects on organ development [21]. Early weaning can cause extensive production of reactive oxygen species and result in oxidative stress, which is implicated in the induction of uncontrolled apoptosis [21]. Therefore, the effects of spermine supplementation on apoptosis genes were determined. Bax and caspase- 3 are two typical pro-apoptotic genes. Bax is associated with powerful deathpromoting capacity, causing the release of cytochrome $\mathrm{c}$ and a reduction in the mitochondrial membrane potential [22]. Caspase- 3 is a member of the cysteine-aspartic acid protease 
(Caspase) family that can be activated by a variety of signals, including extrinsic and intrinsic pathways, and it becomes active when cleaved by an initiator caspase [23]. Following this condition, caspase- 3 plays a central role in the execution phase of cell apoptosis [22]. A summary of data obtained from this study showed that spermine supplementation significantly down-regulated Bax and caspase-3 mRNA levels in the thymus and spleen of piglets. Further correlation analysis indicated that Bax and caspase- 3 gene expression were positively correlated with p21 mRNA level $\left(r_{\text {Bax-spleen }}=\right.$ $+0.861, P_{\text {Bax-spleen }}=0.006^{\star *} ; r_{\text {caspase-3-spleen }}=+0.874, P_{\text {caspase-3-spleen }}$ $\left.=0.005^{\star *} ; r_{\text {caspase-3-thymus }}=+0.776, P_{\text {caspase-3-thymus }}=0.024^{*}\right)$, but negatively associated with cyclin A2 mRNA expression $\left(r_{\text {Bax-spleen }}=-0.960, P_{\text {Bax-spleen }}=0.000^{* *} ; r_{\text {Bax-thymus }}=-0.905\right.$, $P_{\text {Bax-thymus }}=0.002^{* *} ; r_{\text {caspase-3-spleen }}=-0.961, P_{\text {caspase-3-spleen }}=0.000^{* *}$; $r_{\text {caspase-3-thymus }}=-0.941, P_{\text {caspase-3-thymus }}=0.000^{* *}$ ), which is consistent with the above-mentioned results that spermine administration enhanced cell proliferation.

Subsequent to this discovery, the relationship between spermine intake and an anti-apoptotic gene was also determined in this study. Bcl-2, an important cell death-regulating gene, is distributed mainly in the outer membrane of the mitochondria and is considered as the major anti-apoptotic gene responsible for preventing cell apoptosis induced by numerous stimuli [22]. In this paper, spermine supplementation significantly improved Bcl-2 mRNA level in the thymus and spleen. We also observed that $\mathrm{Bcl}-2$ gene expression was negatively correlated with Bax mRNA level $\left(r_{\text {spleen }}=-0.911, P_{\text {spleen }}=0.002^{* *}\right.$; $r_{\text {thymus }}=-0.891, P_{\text {thymus }}=0.003^{* *}$ ) and caspase- 3 mRNA expres$\operatorname{sion}\left(r_{\text {spleen }}=-0.892, P_{\text {spleen }}=0.003^{* *} ; r_{\text {thymus }}=-0.924, P_{\text {thymus }}=\right.$ $\left.0.001^{* *}\right)$, which supported the fact that $\mathrm{Bcl}-2$ regulates apoptosis by activating genes in the caspase family [24], suggesting that spermine administration increased anti-apoptotic gene expression might be partly attributed to reduced pro-apoptotic gene mRNA levels. Notably, there were no difference in cell apoptosis-related gene expressions of the thymus and spleen when piglets fed with $7 \mathrm{~h}$ of spermine intake, which is consistent with the results that spermine supplementation $(7 \mathrm{~h})$ did not affect immunity-related gene expressions [3]. This effect may be due to spermine taking some time to develop physiological function. Moreover, prolonged spermine supplementation markedly down-regulated gene expression of Bax and caspase-3, and up-regulated Bcl-2 mRNA level both in the thymus and spleen, with optimal effects after $6 \mathrm{~d}$ of spermine administration. Together, these observations suggested that spermine supplementation may inhibit cell apoptosis, and a period of $6 \mathrm{~d}$ of spermine supplementation exerts such optimal effects.

Changes in the amino acid transporters in the thymus and spleen of piglets with spermine ingestion

It is well-known that the absorption of amino acids rely on the function of their corresponding transporters, and functional defects of these transporters can lead to aminoaciduria or malabsorption. In addition, piglets need abundant nutrients and energy to meet exuberant growth and metabolism, and spermine derives from the precursor for the synthesis of arginine. Considering these facts, in this experiment, alterations in amino acid transporters expression were investigated along with spermine intake. SLC15A1 is the proton oligopeptide cotransporter that provides peptide substrates for intestinal and renal epithelial cells [25]. Dietary spermine supplementation markedly increased SLC15A1 mRNA levels in the thymus and spleen which implied that spermine intake may partly promote the growth of immune organs by accelerating oligopeptide synthesis. SLC1A1, as a representative glutamate transporter, can provide the substance and energy required for cellular metabolism through adjusting the cellular absorption of glutamate [26]. In this study, spermine administration significantly improved gene expressions of SLC1A1 in the thymus and spleen of piglets. Further correlation analysis demonstrated that SLC1A1 mRNA level was positively related to cyclin A2 gene expression $\left(r_{\text {spleen }}=+0.931, P_{\text {spleen }}=0.001^{* *}\right.$; $\left.r_{\text {thymus }}=+0.964, P_{\text {thymus }}=0.000^{* *}\right)$ and negatively associated with p21 mRNA expression $\left(r_{\text {spleen }}=-0.909, P_{\text {spleen }}=0.002^{* *}\right.$; $\left.r_{\text {thymus }}=-0.814, P_{\text {thymus }}=0.014^{\star}\right)$, supporting that glutamine has beneficial effects on cell proliferation [27].

SLC1A5 and SLC6A19 are two high-affinity amino acid transporters that play important roles in electroneutral exchange of amino acids accompanied by co-transport of sodium [28]. Our study discovered that spermine supplementation promoted an increase in the SLC1A5 mRNA level of the thymus and spleen; no such effects were obtained for the SLC6A19 gene expression, which may be correlated with the tissue differences as described by the previous results observed in the ileum (data not shown).

Additionally, the SLC7 family is usually allocated into two subgroups, the cationic amino acid transporters (e.g., SLC7A1) and glycoprotein-related amino acid transporters (e.g., SLC7A7 and SLC7A9) [29]. SLC7A1 aids in transporting cationic amino acid via accelerated diffusion with differential trans-stimulation caused by some intracellular substrates, and it affects the modulation of the rate of nitric oxide synthesis by controlling the uptake of the substrate of nitric oxide synthase (L-arginine) [30]. The functions of SLC7A7 and SLC7A9 are diverse due to their substrate selectivity, and they mostly act as obligatory exchangers. They have selective functions in transporting neutral amino acids (system $\mathrm{L}$ and asc, Ala, Ser, and Cys-preferring), aromatic amino acids (Tyr, Phe, and Try), and negatively charged amino acids (system $\mathrm{x}_{c}^{-}$) [30]. In the current study, spermine supplementation at a level of 0.4 $\mathrm{mmol} / \mathrm{kg} \mathrm{BW} / 24 \mathrm{~h}$ enhanced the gene expressions of SLC7A1 and SLC7A7 in the thymus and spleen, as well as that of SLC7A9 in the spleen. which is similar to the results of a pre- 
vious study showing that dietary arginine supplementation enhanced ileac SLC7A1 and SLC7A7 mRNA levels [9]. In addition, extended spermine supplementation significantly increased SLC7A7, SLC1A1, SLC15A1, and SLC1A5 gene expressions in the thymus and spleen, SLC7A1 mRNA expression in the thymus and SLC7A9 mRNA abundance in the spleen. Findings suggest that spermine supplementation and its extended duration may modulate amino acid transporters, and such effects were optimal after $6 \mathrm{~d}$ of spermine administration. However, the detailed mechanism by which spermine supplementation controlled amino acid transporters gene expression in piglets needs further investigation.

\section{CONCLUSION}

The results suggesting that spermine supplementation (0.4 $\mathrm{mmol} / \mathrm{kg} \mathrm{BW} / 24 \mathrm{~h}$ ) and its extended duration may modulate cell cycle during the G1/S phase, suppress apoptosis and regulate amino acid transport of the thymus and spleen of piglets in a time-dependent manner, and extended spermine supplementation $(6 \mathrm{~d})$ exerts the optimal effects.

\section{CONFLICT OF INTEREST}

We certify that there is no conflict of interest with any financial organization regarding the material discussed in the manuscript.

\section{ACKNOWLEDGMENTS}

The current study was financially supported by the National Natural Science Foundation of China (No.31301986), the Academy of Kechuang Feed Industry in Sichuan and Specific Research Supporting Program for Discipline Construction in Sichuan Agricultural University (to G. Liu).

\section{REFERENCES}

1. Fang T, Liu G, Cao W, et al. Spermine: new insights into the intestinal development and serum antioxidant status of suckling piglets. RSC Adv 2016;6:31323-35.

2. Liu G, Fang T, Yan T, et al. Metabolomic strategy for the detection of metabolic effects of spermine supplementation in weaned rats. J Agric Food Chem 2014;62:9035-42.

3. Cao W, Wu X, Jia G, et al. New insights into the role of dietary spermine on inflammation, immune function and relatedsignalling molecules in the thymus and spleen of piglets. Arch Anim Nutr 2017;71:175-91.

4. Pegg AE. The function of spermine. IUBMB Life 2014;66:818.

5. Liu GM, Yan T, Fang TT, et al. Nutrimetabolomic analysis provides new insights into spermine-induced ileum-system alterations for suckling rats. RSC Adv 2015;5:48769-78.

6. Krüger A, Vowinckel J, Mülleder M, et al. Tpo1-mediated spermine and spermidine export controls cell cycle delay and times antioxidant protein expression during the oxidative stress response. EMBO Rep 2013;14:1113-9.

7. Nitta T, Igarashi K, Yamashita A, Yamamoto M, Yamamoto $\mathrm{N}$. Involvement of polyamines in B cell receptor-mediated apoptosis: spermine functions as a negative modulator. Exp Cell Res 2001;265:174-83.

8. Miller ER, Ullrey DE. The pig as a model for human nutrition. Annu Rev Nutr 1987;7:361-82.

9. Yin J, Ren W, Duan J, et al. Dietary arginine supplementation enhances intestinal expression of SLC7A7 and SLC7A1 and ameliorates growth depression in mycotoxin-challenged pigs. Amino Acids 2014;46:883-92.

10. National Research Council (NRC). Nutrient requirements of swine. Washington, DC, USA: National Academy Press; 1998.

11. Cheng ZB, Li DF, Xing JJ, Guo XY, Li ZJ. Oral administration of spermine advances intestinal maturation in sucking piglets. Anim Sci 2006;82:621-6.

12.Pfaffl MW. A new mathematical model for relative quantification in real-time RT-PCR. Nucleic Acids Res 2001;29:e45.

13. Livak KJ, Schmittgen TD. Analysis of relative gene expression data using real-time quantitative PCR and the 2(-Delta Delta C(T)) method. Methods 2001;25:402-8.

14. Romain N, Dandrifosse G, Jeusette F, Forget P. Polyamine concentration in rat milk and food, human milk, and infant formulas. Pediatr Res 1992;32:58-63.

15. Hwang HC, Clurman BE. Cyclin E in normal and neoplastic cell cycles. Oncogene 2005;24:2776-86.

16. Bedelbaeva K, Snyder A, Gourevitch D, et al. Lack of p21 expression links cell cycle control and appendage regeneration in mice. Proc Natl Acad Sci USA 2010;107:5845-50.

17.Zhao Z, Liu J, Wang C, et al. MicroRNA-25 regulates small cell lung cancer cell development and cell cycle through cyclin E2. Int J Clin Exp Pathol 2014;7:7726-34.

18. Sankaran VG, Ludwig LS, Sicinska E, et al. Cyclin D3 coordinates the cell cycle during differentiation to regulate erythrocyte size and number. Genes Dev 2012;26:2075-87.

19. Gong D, Ferrell JE Jr. The roles of cyclin A2, B1, and B2 in early and late mitotic events. Mol Biol Cell 2010;21:3149-61.

20. Yang SD, Bai ZL, Zhang F, et al. Levofloxacin increases the effect of serum deprivation on anoikis of rat nucleus pulposus cells via Bax/Bcl-2/caspase-3 pathway. Toxicol Mech Methods 2014;24:688-96.

21.Loh KP, Huang SH, De Silva R, Tan BK, Zhu YZ. Oxidative stress: apoptosis in neuronal injury. Curr Alzheimer Res 2006; 3:327-37.

22. Wu B, Cui H, Peng X, et al. Dietary nickel chloride induces oxidative stress, apoptosis and alters $\mathrm{Bax} / \mathrm{Bcl}-2$ and caspase- 3 mRNA expression in the cecal tonsil of broilers. Food Chem Toxicol 2014;63:18-29. 
23.Zheng TS, Flavell RA. Divinations and surprises: genetic analysis of caspase function in mice. Exp Cell Res 2000;256:67-73.

24. Antonsson B, Martinou JC. The Bcl-2 protein family. Exp Cell Res 2000;256:50-7.

25.Daniel H, Kottra G. The proton oligopeptide cotransporter family SLC15 in physiology and pharmacology. Pflugers Arch 2004;447:610-8.

26. Kristensen AS, Andersen J, Jørgensen TN, et al. SLC6 neurotransmitter transporters: structure, function, and regulation. Pharmacol Rev 2011;63:585-640.
27. Roth E. Immune and cell modulation by amino acids. Clin Nutr 2007;26:535-44.

28. Kanai Y, Clémençon B, Simonin A, et al. The SLC1 high-affinity glutamate and neutral amino acid transporter family. Mol Aspects Med 2013;34:108-20.

29. Verrey F, Closs EI, Wagner CA, et al. CATs and HATs: the SLC7 family of amino acid transporters. Pflugers Arch 2004;447: 532-42.

30. Fotiadis D, Kanai Y, Palacín M. The SLC3 and SLC7 families of amino acid transporters. Mol Aspects Med 2013;34:139-58. 